\title{
PENGGUNAAN MEDIA EDUKASI HITUNG KOMPAK TERHADAP KEMAMPUAN BERHITUNG CAMPURAN DI SEKOLAH DASAR
}

\author{
Ernawati \\ Program Studi Pendidikan Guru Sekolah Dasar, Fakultas Keguruan dan Ilmu \\ Pendidikan, Universitas Muhammadiyah Makassar, Jl. Sultan Alauddin No.259, \\ Makassar, Indonesia 90221
}

\begin{abstract}
One of the subjects that must consider new strategies in primary school is Math. Because at the elementary level in Mathematics awarded to equip learners with the ability to think logically, analytical, systematic, critical, and creative, as well as the ability to cooperate. In an effort to improve numeracy skills mix of students still need a method or medium of learning effective, interesting, and fun student. The use of educational media Calculate Compact on mathematics learning process is a variation in the learning process to create a learning process with the nuances of playing, so that students do not feel tired and bored in following math learning in the classroom. Media education Calculate Compact is a medium that is designed to solve the problem of mathematics which consists of board-based board game of snakes and is equipped with
\end{abstract}

Keywords: Calculate Media Education Compact, numeracy mix, Elementary School

\begin{abstract}
Abstrak
Salah satu mata pelajaran yang harus memperhatikan strategi baru di Sekolah Dasar adalah Matematika. Sebab pada tingkat SD mata pelajaran Matematika diberikan untuk membekali peserta didik dengan kemampuan berpikir logis, analitis, sistematis, kritis, dan kreatif, serta kemampuan bekerjasama. Sebagai upaya meningkatkan kemampuan berhitung campuran siswa masih dibutuhkan suatu metode atau media pembelajaran yang efektif, menarik, dan menyenangkan siswa. Penggunaan media edukasi Hitung Kompak pada proses pembelajaran matematika merupakan variasi dalam proses pembelajaran yang dapat menciptakan proses pembelajaran dengan nuansa bermain, sehingga siswa tidak merasa jenuh dan bosan dalam mengikuti pembelajaran matematika di kelas. Media edukasi Hitung Kompak merupakan suatu media yang didesain untuk memecahkan masalah pembelajaran matematika yang terdiri atas, papan alas berbasis permainan ular tangga dan dilengkapi dengan kartu hitung dari kertas berwarna.
\end{abstract}

Kata kunci: Media Edukasi Hitung Kompak, kemampuan berhitung campuran, Sekolah Dasar 


\section{Pendahuluan}

Salah satu mata pelajaran yang harus memperhatikan strategi baru di Sekolah Dasar adalah Matematika. Sebab pada tingkat SD mata pelajaran Matematika diberikan untuk membekali peserta didik dengan kemampuan berpikir logis, analitis, sistematis, kritis, dan kreatif, serta kemampuan bekerjasama. Kompetensi tersebut diperlukan agar peserta didik dapat memiliki kemampuan memperoleh, mengelola, dan memanfaatkan informasi untuk bertahan hidup pada keadaan yang selalu berubah, tidak pasti, dan kompetitif. Selain untuk mengembangkan kemampuan tersebut, dimaksudkan pula untuk mengembangkan kemampuan menggunakan matematika dalam pemecahan masalah dan mengomunikasikan ide atau gagasan dengan menggunakan simbol, tabel, diagram, dan media lain.

Masalah utama dalam pembelajaran matematika adalah masih rendahnya daya serap peserta didik. Permasalahan ini tampak dari rerata hasil belajar peserta didik yang masih sangat memprihatinkan. Di sekolah, banyak siswa tampaknya menjadi tidak tertarik dengan matematika, ini dikarenakan belum tepatnya cara penyampaian materi kepada siswa sehingga menyebabkan siswa kesulitan dalam menerima pelajaran. Sebagian besar guru masih mengimplementasikan pembelajaran matematika tradisional yaitu pembelajaran matematika dengan mengandalkan metode tunggal ekspositori dengan siklus; menjelaskan, memberi contoh, mengajukan pertanyaan, dan memberi tugas secara

klasikal. Metode seperti ini mengakibatkan proses pembelajaran berpusat pada guru (student centered) dan proses pembelajaran hanya dikuasai oleh guru. Sehingga minat

siswa dalam pembelajaran matematika kurang yang mengakibatkan pemahaman dan penguasaan materi cenderung rendah. Kondisi tersebut akhirnya berdampak pada hasil belajar siswa yang kurang maksimal.

Karim dalam (Puspitasari, 2012: 100) menyatakan bahwa guru matematika sekolah dasar harus memahami materi yang akan diajarkan, memahami dan memanfaatkan dengan baik cara peserta didik belajar matematika, serta memahami dan menerapkan cara memanfaatkan alat bantu belajar mengajar matematika.

Media edukasi Hitung Kompak merupakan suatu media yang didesain untuk memecahkan masalah pembelajaran matematika yang terdiri atas, papan alas berbasis permainan ular tangga dan dilengkapi dengan kartu hitung dari kertas berwarna. Penggunaan media edukasi Hitung Kompak pada proses pembelajaran matematika merupakan variasi dalam proses pembelajaran yang dapat menciptakan proses pembelajaran dengan nuansa bermain, sehingga siswa tidak merasa jenuh dan bosan dalam mengikuti pembelajaran matematika di kelas.

\section{Metode Penelitian}

Penelitian ini adalah penelitian eksperimen dengan melibatkan satu kelompok atau satu kelas yang dikenal dengan desain pra eksperimen. Dengan tujuan untuk mengetahui gambaran penggunaan media edukasi Hitung Kompak terhadap kemampuan berhitung campuran pada siswa Sekolah Dasar.

Penelitian yang dilakukan adalah jenis pra-eksperimen dengan rancangan One Group Pretest-Posttest Design. Adapun cara atau teknik dalam pengambilan sampel yang digunakan adalah teknik random sampling atau biasa juga diberi istilah pengambilan sampel secara rambang atau acak.

Teknik random sampling merupakan teknik pengambilan sampel dimana semua dalam populasi baik secara sendiri-sendiri atau bersama-sama diberi kesempatan yang sama untuk dipilih menjadi anggota sampel tanpa pilih-pilih atau tanpa pandang buluh, didasarkan atas prinsip-prinsip matematika yang diuji dalam praktek. Karenanya 
dipandang sebagai teknik sampling paling baik dalam penelitian. Teknik pengumpulan data yang digunakan dalam penelitian ini adalah tes awal dan tes akhir dan teknik analisis data yang digunakan adalah analisis deskriptif dan analisis inferensial.

\section{Hasil Dan Pembahasan}

Data Pretest kemampuan berhitung campuran pada siswa Sekolah Dasar.

Tabel 1. Distribusi Nilai, Frekuensi, dan Persentase Kemampuan Berhitung Campuran pada Siswa Sekolah Dasar Sebelum Menggunakan Media Edukasi Hitung Kompak (Pretest)

\begin{tabular}{|c|c|c|c|}
\hline No & Nilai & $\begin{array}{c}\text { Frekuensi } \\
\text { (f) }\end{array}$ & $\begin{array}{c}\text { Persentase } \\
\text { (\%) }\end{array}$ \\
\hline 1 & 80 & 1 & 3,7 \\
\hline 2 & 70 & 1 & 3,7 \\
\hline 3 & 60 & 7 & 25,9 \\
\hline 4 & 50 & 18 & 66,7 \\
\hline \multicolumn{2}{|c|}{ Jumlah } & 27 & 100 \\
\hline
\end{tabular}

Tabel 2. Distribusi Nilai, Frekuensi, dan Persentase Kemampuan Berhitung Campuran pada Siswa Sekolah Dasar Setelah Menggunakan Media Edukasi Hitung Kompak (Protest)

\begin{tabular}{|c|c|c|c|}
\hline No & Nilai & $\begin{array}{c}\text { Frekuensi } \\
\text { (f) }\end{array}$ & $\begin{array}{c}\text { Persentase } \\
\text { (\%) }\end{array}$ \\
\hline 1 & 100 & 6 & 22,2 \\
\hline 2 & 80 & 5 & 18,5 \\
\hline 3 & 70 & 16 & 59,3 \\
\hline \multicolumn{2}{|c|}{ Jumlah } & 27 & 100 \\
\hline
\end{tabular}

Dalam penelitian ini hipotesis yang diajukan adalah "ada pengaruh penggunaan media edukasi Hitung Kompak terhadap kemampuan berhitung campuran”. Untuk mengetahui berpengaruh atau tidaknya penggunaan media edukasi Hitung Kompak sebelum (pretest) dan setelah diberi perlakuan (posttest) digunakan analisis Uji T (t-test)

a. Menentukan/mencari harga Md (Mean dari perbedaan antara pre test dan post test) (terlampir).

b. Menentukan/mencari harga $\sum X^{2} d$ (terlampir).

c. Menentukan harga T Hitung (terlampir).

d. Menentukan harga t Tabel (terlampir):

Untuk mencari t Tabel peneliti menggunakan tabel distribusi t dengan taraf signifikan $\alpha=0,05$ dan d.b. $=\mathrm{N}-1=27-1=26$ (terlampir).

Berdasarkan tabel $t$, maka diperoleh $t_{0,05}=3,707$. Setelah diperoleh $t$ Hitung $=10,56$ dan $\mathrm{t}$ Tabel $=3,707$ maka $\mathrm{t}$ Hitung $\geq \mathrm{t}$ Tabel atau $10,56 \geq 3,707$. Sehingga dapat disimpulkan bahwa $\mathrm{H}_{0}$ ditolak dan $\mathrm{H}_{1}$ diterima. Ini berarti bahwa penggunaan media edukasi hitung 
kompak memiliki pengaruh terhadap kemampuan berhitung campuran pada siswa Sekolah Dasar. Dalam pengujian statistik, hipotesis ini dinyatakan sebagai berikut:

$$
H_{0}: t_{\text {hitung }} \leq t_{\text {tabel lawan }} H_{1}: t_{\text {hitung }} \geq t_{\text {tabel }}
$$

\section{Kesimpulan}

Penggunaan media edukasi Hitung Kompak, kemampuan berhitung campuran siswa dikategorikan memadai dengan semua siswa mampu memperoleh nilai di atas 70 (100\%).

Pengaruh penggunaan media edukasi Hitung Kompak, diketahui pula berdasarkan perhitungan uji t. Perbandingan hasil kemampuan pretest dan posttest menunjukkan bahwa nilai $t_{\text {hitum }}$ sebanyak 10,56 > t Tabel $=3,707$. Hal ini menunjukkan bahwa hipotesis penelitian yang diajukan diterima.

\section{Ucapan Terima Kasih}

Penulis menyampaikan ucapan terima kasih kepada Dr. H. Abd. Rahman Rahim, SE., M.M., Rektor Universitas Muhammadiyah Makassar, Dr. A. Sukri Syamsuri, M.Hum., Dekan FKIP Universitas Muhammadiyah Makassar, Sulfasyah, MA., Ph.D., Ketua Jurusan PGSD FKIP Unismuh Makassar.

\section{Daftar Pustaka}

Abdurrahman. 2003. Pendidikan Bagi Anak Berkesulitan Belajar. Jakarta: PT Rineka Cipta.

Arikunto, Suharsimi. 2006. Prosedur Penelitian Suatu Pendekatan Praktek. Jakarta: Rineka Cipta.

Danim, Sudarwan. 2010. Media Komunikasi Pendidikan: Pelayana Profesional Pembelajaran. Jakarta: Bumi Aksara.

Endah, Murniati. 2012. Mengajarkan Matematika dengan Fun. Yogyakarta: Mentari Pustaka.

Ezmir. 2007. Metodologi Penelitian Pendidikan, Kualitatif dan Kuantitatif. Jakarta : PT. Raja Grafindo Persada.

Ismayani, Ani. 2010. Fun Math with Children. Jakarta: PT Elex Media Komputindo.

Marisa, dkk. 2011. Komputer dan Media Pembelajaran. Jakarta: Universitas Terbuka.

Montolalu, dkk. 2005. Bermain dan Permainan Anak. Jakarta: Universitas Terbuka.

Sadiman, Arief S., dkk. 2005. Media Pendidikan. Jakarta: PT Raja Grafindo Persada.

Subarinah, Sri. 2006. Inovasi Pembelajaran Matematika SD. Jakarta: Depdiknas.

Sugiono. 2014. Metode Penelitian Kuantitatif, Kualitatif dan $R \&$ D. Bandung: Alfabeta.

Sriyanto. 2010. Pengertian Kemampuan, (Online), (http://ian43.wordpress.com/2010/12/23/pengertian-kemampuan/diakses pada 29 Juni 2016).

Suja'I. 2008. Inovasi Pembelajaran Bahasa Arab. Semarang: Walisongo Press.

Suparman, M. Atwi. 2011. Desain Instruksional. Jakarta: PAU-PPI. 